ORIGINAL

\title{
Actividad antibacteriana de la cáscara de cacao, Theobroma cacao L
}

\author{
Antibacterial activity of the cacao bean husk, \\ Theobroma cacao L
}

\author{
Oscar Cuéllar G, ${ }^{1}$ Tecnol Quím, Gloria Guerrero A, ${ }^{1 *}$ Ph.D.
}

${ }^{1}$ Universidad Tecnológica de Pereira. Facultad de Tecnología. Escuela de Tecnología Química. Grupo de Oleoquímica. Pereira, Colombia.*Correspondencia: gguerrero@utp.edu.co

Recibido: Agosto de 2011; Aceptado: Febrero de 2012.

\section{RESUMEN}

Objetivo. Evaluar la actividad antibacteriana de diferentes fracciones de la cáscara de cacao (Theobroma cacao L.). Materiales y métodos. Se evaluó la actividad antibacteriana mediante el método de difusión en agar de diferentes fracciones de la cáscara de cacao, empleando cepas autóctonas y de referencia ATCC. Posteriormente, se hizo un análisis de estas fracciones por cromatografía líquida de alta eficiencia y cromatografía de gases acoplada a espectrometría de masas. Resultados. La fracción clorofórmica presentó actividad antibacteriana frente a Bacillus cereus ATCC 11778 y Streptococcus agalactiae (autóctona), con porcentajes de inhibición de $34.90 \%(100 \mu \mathrm{g} / \mu \mathrm{l}$ ) y $52.40 \%(100 \mu \mathrm{g} / \mu \mathrm{l})$ respectivamente. También se evidenció una concentración mínima inhibitoria de $512 \mu \mathrm{g} / \mathrm{ml}$ frente a Bacillus cereus ATCC 11778 y de $128 \mu \mathrm{g} / \mathrm{ml}$ frente a Streptococcus agalactiae. Conclusiones. Este trabajo es el primer reporte a saber en Colombia sobre actividad antibacteriana in vitro de la cáscara de cacao, el cual resulta ser un avance importante para esta agroindustria. Esta investigación abre paso a otros estudios relacionados para establecer el espectro de inhibición frente a otros microorganismos.

Palabras clave: Actividad antibacteriana, Bacillus cereus, Streptococcus agalactiae (Fuente: DeCS).

\begin{abstract}
Objective. To test the antibacterial activity of different fractions of cacao bean husk (Theobroma cacao L.). Materials and methods. Antibacterial activity of different fractions of cacao bean husk was analyzed using agar diffusion method with native and ATCC strains. These fractions were studied by HPLC and GC/MS. Results. The Chloroform fraction exhibited antibacterial activity through an inhibition percentage of $34.90 \%(100 \mu \mathrm{g} / \mu \mathrm{l})$ for Bacillus cereus ATCC 11778 and $52.40 \%(100 \mu \mathrm{g} / \mu \mathrm{l})$ for Streptococcus agalactiae (native). It also showed $512 \mu \mathrm{g} / \mathrm{ml}$ as a minimum inhibitory concentration for Bacillus cereus and $128 \mu \mathrm{g} / \mathrm{ml}$ for Streptococcus agalactiae. Conclusions. This research is the first report known in Colombia about cacao bean husk exhibiting in vitro antibacterial activity, which is an important advance for the cacao industry. This work opens the door for further related studies to determine the spectrum of inhibition with other microorganisms.
\end{abstract}

Key words: Antibacterial activity, Bacillus cereus, Streptococcus agalactiae (Source: DeCS). 


\section{INTRODUCCIÓN}

El cacao (Theobroma cacao L.) pertenece a la familia Sterculiaceae, es una planta que crece en una franja geográfica fundamentalmente tropical y se extiende $20^{\circ}$ de latitud hacia ambos hemisferios. Se clasifica en dos grandes grupos: Criollo y Forastero y según la Organización Internacional del Cacao (ICCO), esta última es una variedad con gran crecimiento, debido a la mayor facilidad para su siembra y manejo (1). El cacao se utiliza principalmente para la producción de chocolate siendo el continente Africano el mayor productor con el $59 \%$ de la oferta mundial, liderado por Costa de Marfil con 1.000 .000 de toneladas que representan el 34\% de la producción mundial (2).

El grano de cacao y las hojas del árbol han sido estudiados por diversos autores en lo que se refiere a la composición química de fenoles, alcaloides, ácidos grasos y carbohidratos $(3,4)$, también se han reportado estudios de actividad antioxidante (5), de la caracterización química de la manteca de cacao así como de sus aplicaciones (6). Respecto a la cáscara de cacao que es el principal desecho de esta industria, se han desarrollado estudios donde se utiliza para la alimentación de porcinos y gallos $(7,8)$, como fuente comercial de pectinas (9), en la producción de espumas de poliuretano para uso hortícola (10) y algunos hacen referencia a la actividad antibacteriana de extractos de la cáscara de cacao frente a Streptococcus mutans $(11,12)$.

En Colombia, el $25 \%$ del cacao producido se clasifica como de sabor y fino aroma, el cual se emplea para darle características especiales a los chocolates. El departamento que tradicionalmente ha concentrado la mayor producción de cacao es Santander con el 30.06\% de participación del total de la producción en el año 2010 de 68.987 toneladas. En ese mismo año $69.7 \%$ de las exportaciones de Colombia se dirigieron principalmente a países del continente americano como Ecuador, Panamá, Venezuela y Estados Unidos (13).

La manteca de cacao producida en Colombia se utiliza como ingrediente en la elaboración de productos de chocolatería, y la cáscara de cacao que se genera luego del proceso de tostado es el principal desecho en la cadena de producción de chocolate representando el 10\% (14). El contenido de teobromina en la cáscara de cacao restringe la proporción en que puede ser suministrada como complemento en la nutrición de rumiantes, debido a la toxicidad de este alcaloide (15).
Investigaciones recientes en Colombia, indican que la cáscara de cacao puede ser utilizada como ingrediente principal en la formulación de galletas para personas con estreñimiento (16), adicionalmente el mucílago de este desecho puede ser una alternativa para la clarificación de jugos en la industria panelera (17).

El objetivo del presente trabajo fue buscar nuevas posibilidades de uso del principal desecho en la producción de chocolate: la cáscara, evaluando la actividad antibacteriana de diferentes fracciones, utilizando cepas ATCC y autóctonas.

\section{MATERIALES Y MÉTODOS}

Material vegetal. Se empleó cáscara residual molida de cacao, Theobroma cacao L. (mezcla de diferentes tipos de granos tostados) suministrada por la empresa Casa Luker. Esta fue llevada al Laboratorio de Oleoquímica de la Universidad Tecnológica de Pereira, donde se almacenó en bolsas plásticas a $4^{\circ} \mathrm{C}$.

\section{Obtención y fraccionamiento del extracto etanol absoluto: agua (1:1) de la cáscara de cacao. La extracción se llevó a cabo con cáscara de cacao molida previamente desengrasada con hexano. Se utilizó como solvente una mezcla de etanol absoluto:agua (1:1). Se emplearon 20 gramos de cáscara y $100 \mathrm{ml}$ de solvente, usando agitación magnética, una temperatura de $25^{\circ} \mathrm{C}$ y un tiempo de extracción de 2 horas. El extracto crudo se filtró al vacío a través de papel filtro Whatman No. 4 y el filtrado se conservó protegido de la luz a $4^{\circ} \mathrm{C}$.}

Se hizo un fraccionamiento líquido-líquido del extracto crudo empleando cloroformo, acetato de etilo y $n$-butanol. En cada caso se realizaron extracciones sucesivas por triplicado con una relación $1: 1$ de volumen de extracto vs., volumen de solvente. Las fases orgánicas obtenidas se filtraron al vacío, se concentraron por rota-evaporación y el solvente residual se eliminó por corriente de nitrógeno.

Actividad antibacteriana. Se utilizó como blanco dimetilsulfóxido (DMSO) al $99 \%$ y como control de inhibición se empleó ampicilina (25 $\mu \mathrm{g} / \mu \mathrm{l}$ ) para Pseudomonas aeruginosa ATCC 27853; amoxicilina $(5 \mu \mathrm{g} / \mu \mathrm{l})$ para Bacillus cereus ATCC 11778 y Streptococcus agalactiae aislado de un paciente en el Laboratorio Clínico Patológico López Correa (Pereira, Colombia); ciprofloxacina $(0.125 \mu \mathrm{g} / \mu \mathrm{l})$ para Escherichia coli "resistente a amoxicilina" aislada de pollo 
y micostatina $(5 \mu \mathrm{g} / \mu \mathrm{l})$ para Candida albicans ATCC 10231. La fracción clorofórmica, en acetato de etilo y butanólica se solubilizaron en DMSO al $99 \%$ a las concentraciones de 100,50 y 25 $\mu \mathrm{g} / \mu \mathrm{l}$. El bioensayo se realizó por el método de difusión en agar, una modificación del método desarrollado por Kirby-Bauer (18). Cada bacteria fue replicada en dos tubos de ensayo con el medio líquido infusión-cerebro-corazón (BHI) y caldo Sauboraud para Candida albicans ATCC 10231.

Se ajustó la absorbancia a 0.1 , que corresponde a 0.5 en la escala Mc Farland con una concentración de $1.5 \cdot 10^{8} \mathrm{UFC} / \mathrm{ml}$ de las bacterias y del hongo a una longitud de onda de 540 y $490 \mathrm{~nm}$ respectivamente, empleando un espectrofotómetro Génesis 10 (Marca: Termospectronic, Fabricante: Termospectronic, Ciudad: New York, País: USA), y usando como blanco el medio líquido respectivo. Se adicionaron $100 \mu \mathrm{l}$ de la bacteria u hongo según el caso a una caja de Petri, luego se añadieron $25 \mathrm{ml}$ de agar Müeller-Hinton a $50^{\circ} \mathrm{C}$. Se homogenizó, se perforaron 5 pozos los cuales se sellaron con $20 \mu \mathrm{l}$ del mismo agar. En el pozo central se adicionó $10 \mu$ le DMSO al 99\% (como blanco), a los cuatro pozos restantes en su orden de izquierda a derecha se adicionó $10 \mu \mathrm{ldel}$ antibiótico respectivo y la fracción clorofórmica, en acetato de etilo y butanólica en cada caso a las concentraciones establecidas anteriormente. Se incubó por 24 horas a una temperatura de $37^{\circ} \mathrm{C}$, utilizando una incubadora VELP (Marca: Scientifica, Fabricante: Scientifica, Ciudad: Milano, País: Italia). Se hizo la medición del diámetro del halo de inhibición de la fracción que fue objeto de estudio con respecto al del control para permitir un control estadístico del factor inhibitorio.

Determinación de la concentración mínima inhibitoria. Se utilizó ciprofloxacina como control positivo de inhibición en DMSO al 99\% para Bacillus cereus ATCC 11778 y amoxicilina para Streptococcus agalactiae autóctona. La concentración mínima inhibitoria se realizó por dilución en microplaca de 96 pozos (19). Se preparó una solución stock de cada fracción a una concentración de $64000 \mu \mathrm{g} / \mathrm{ml}$ en DMSO al 99\%, a partir de esta se hicieron diluciones sucesivas desde 1024 hasta $1 \mu \mathrm{g} / \mathrm{ml}$. Se transfirieron $20 \mu \mathrm{l}$ de cada una de las concentraciones a los pozos de una fila enumerados del 1 al 11 y se adicionó el blanco en el pozo número 12 (DMSO al 99\%). Cada fracción se repitió en tres filas, se adicionó a cada pozo $220 \mu \mathrm{l}$ de medio de cultivo líquido (caldo nutritivo) y $10 \mu \mathrm{l}$ del microorganismo ajustado a 0.1 de absorbancia. La lectura inicial se hizo a contra luz observando turbidez o transparencia después de 4 horas de incubación a $37^{\circ} \mathrm{C}$, se tomó como valor de CMI la concentración del primer pozo que presentó transparencia en cada fila. Posteriormente se adicionaron $25 \mu \mathrm{l}$ de Bromuro de 3-(4,5-dimetil2-tiazolil)-2,5-difeniltetrazoilo (MTT) (con una concentración de $0.8 \mathrm{mg} / \mathrm{ml}$ ) utilizando como medio dispersante Triton (con una concentración de $0.1 \mathrm{~g} / \mathrm{ml}$ ) a cada uno de los pozos con el microorganismo y se incubó a $37^{\circ} \mathrm{C}$. La segunda lectura se hizo a través de un método colorimétrico. Como prueba confirmatoria se hizo una siembra por superficie en caja Petri con agar nutritivo, se adicionó $20 \mu \mathrm{l}$ del contenido del pozo y se incubó por 24 horas a $37^{\circ} \mathrm{C}$, posteriormente se realizó la lectura observando inhibición o crecimiento.

Análisis preliminar por cromatografía de capa delgada. Las fracciones clorofórmicas, en acetato de etilo y butanólicas fueron evaluadas preliminarmente mediante cromatografía de capa delgada. Para evaluar la presencia de alcaloides, se empleó como fase estacionaria sílica gel $60 \mathrm{~F}_{254}$, un sistema de elución cloroformo:metanol (9:1), estándares de teobromina (Sigma $\geq 99 \%$, T4500), cafeína (Sigma Reference Standard, C1778) y teofilina (Sigma Anhydrous $\geq 99 \%$, T1633). Para los compuestos fenólicos se utilizó como sistema de elución cloroformo:metanol:agua en proporción (7:13:8), un estándar de ácido ferúlico (Aldrich $99 \%, 128708)$. En ambos casos se reveló con luz ultravioleta a longitud de onda corta (270nm).

\footnotetext{
Análisis de alcaloides y compuestos fenólicos por cromatografía líquida de alta eficiencia. Para el análisis de las diferentes fracciones se empleó un equipo marca Jasco HPLC 2000 Plus (Fabricante: Jasco Corporation, Ciudad: Tokyo, País: Japón), equipado con una bomba de gradiente cuaternario (PU-2089Plus), automuestreador (AS-2059 Plus), horno para columna (CO-2065 Plus), detector de arreglo de diodos (MD-2015 Plus), controlado por software EZCrhom Elite. Se utilizó una Columna UltraAqueous RP-18 RESTEK. Se empleó como fase móvil ácido fosfórico al $0.05 \%(A)$ y acetonitrilo al $5 \%$ (B). Se hizo una elución isocrática con $95 \%$ de A los primeros 5 minutos, luego con gradiente lineal hasta alcanzar $75 \%$ a los 15 minutos y finalmente se mantuvo isocrático por 5 minutos más para un tiempo total de análisis de 20 minutos. Se empleó un tiempo de re-equilibrio de 5 minutos entre cada corrida. La columna se mantuvo a $40^{\circ} \mathrm{C}$, se utilizó un flujo de $0.5 \mathrm{ml} /$ min, un volumen de inyección de $10 \mu \mathrm{l}$ y un rango de longitud de onda para la adquisición de datos entre 230 a $450 \mathrm{~nm}$.
} 
Detección y cuantificación de alcaloides y compuestos fenólicos. La detección de alcaloides en las fracciones se hizo por comparación con el tiempo de retención de estándares de teobromina (Sigma $\geq 99 \%$ T4500), cafeína (Sigma Reference Standard, C1778) y teofilina (Sigma anhydrous $\geq 99 \%$, T1633), eluidos en las mismas condiciones. Para los compuestos fenólicos la detección se realizó empleando un estándar de ácido ferúlico (Aldrich $99 \%, 128708$ ) que fue analizado bajo las mismas condiciones.

La cuantificación de alcaloides y compuestos de tipo fenólico se hizo por el método del estándar externo. Se realizaron curvas de calibración por triplicado, empleando un rango de concentraciones de 6.25 a $200 \mu \mathrm{g} / \mathrm{ml}$ con los estándares respectivos. Los parámetros estadísticos fueron: teobromina: $Y=87684.9 x+135855, R^{2}=0.999292$, D.S $=4875.78, \mathrm{LD}=0.16 \mu \mathrm{g} / \mathrm{ml}, \mathrm{LC}=0.55 \mu \mathrm{g} / \mathrm{ml}$; teofilina: $\mathrm{Y}=61342.1 \mathrm{x}+91287.2, \mathrm{R}^{2}=0.999189$, D.S $=3285.51, \mathrm{LD}=0.16 \mu \mathrm{g} / \mathrm{ml}, \mathrm{LC}=0.54 \mu \mathrm{g} / \mathrm{ml}$; cafeína: $\mathrm{Y}=62519.4 \mathrm{x}+107980, \mathrm{R}^{2}=0.999212$, D. $S=3890.13, L D=0.19 \mu \mathrm{g} / \mathrm{ml}, L C=0.64$ $\mu \mathrm{g} / \mathrm{ml}$; ácido ferúlico: $\mathrm{Y}=32520,6 \mathrm{x}+42144$, $\mathrm{R}^{2}=0.999336$, D. $\mathrm{S}=1980.09, \mathrm{LD}=0.18 \mu \mathrm{g} /$ $\mathrm{ml}, \mathrm{LC}=0.61 \mu \mathrm{g} / \mathrm{ml}$. (LD= Límite de detección, $\mathrm{LC}=$ Límite de cuantificación, D.S = Desviación estándar).

Análisis por cromatografía de gases/ espectrometría de masas de la fracción de alcaloides. Se empleó un cromatógrafo marca Shimadzu QP-2010 (Fabricante: Shimadzu Corporation, Ciudad: Kioto, País: Japón), equipado con un autoinyector (AOC20i)/ automuestreador (AOC-20s, Split 1:20), acoplado a un detector de masas, modo de ionización de impacto electrónico a $70 \mathrm{eV}$, controlado por software GC-MS solution. Se utilizó una Columna capilar Rtx-5 Sil MS. El horno se programó con una temperatura inicial de $100^{\circ} \mathrm{C}$ por 2 minutos, luego se incrementó en una tasa de $10^{\circ} \mathrm{C}$ por minuto hasta alcanzar una temperatura final de $320^{\circ} \mathrm{C}$ que se mantuvo por 10 minutos para un tiempo total de análisis de 34 minutos.

\section{RESULTADOS}

Actividad antibacteriana de la fracción clorofórmica. El porcentaje de inhibición frente a $B$. cereus fue de $34.90 \%$ con la fracción clorofórmica empleando una concentración de $100 \mu \mathrm{g} / \mu \mathrm{l}$ y $31.70 \%$ a una concentración de 50 $\mu \mathrm{g} / \mu \mathrm{l}$ (Figura 1A).

Como se aprecia en la figura 1B, la fracción clorofórmica frente a S. agalactiae presentó

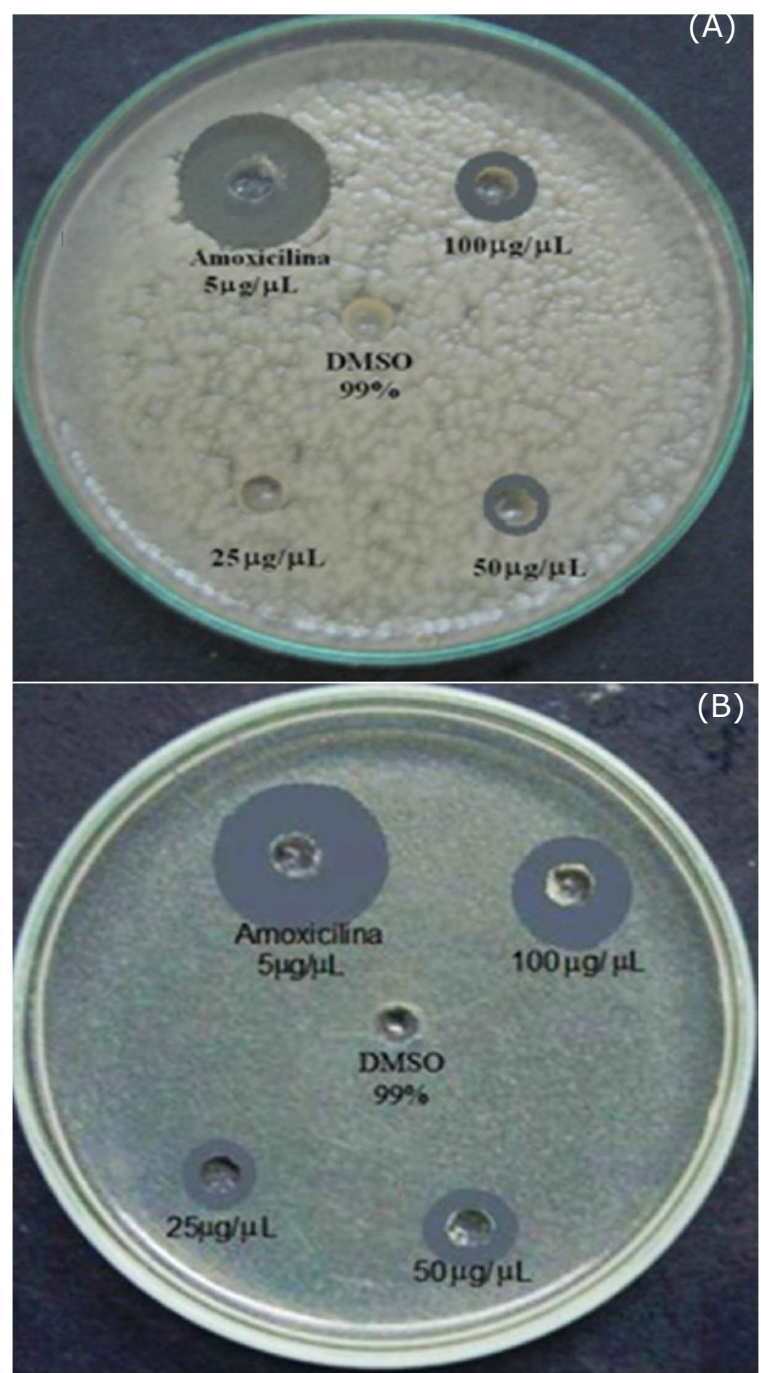

Figura 1. Actividad antibacteriana de la fracción clorofórmica frente a: (A) Bacillus cereus ATCC 11778, (B) Streptococcus agalactiae nativa

porcentajes de inhibición del 33.30\% (25 $\mu \mathrm{g} /$ $\mu \mathrm{l}), 47.80 \%(50 \mu \mathrm{g} / \mu \mathrm{l})$ y del $52.40 \%(100 \mu \mathrm{g} /$ $\mu \mathrm{l})$, destacándose que no hubo gran diferencia entre los dos últimos; lo que podría indicar que a concentraciones mayores de $50 \mu \mathrm{g} / \mu \mathrm{l}$ no se obtendría un incremento considerable de la actividad inhibitoria; sin embargo, se requiere de un estudio detallado frente a este microorganismo que permita establecer con certeza este comportamiento.

En cuanto a los resultados de concentración mínima inhibitoria, la fracción clorofórmica presentó frente a Bacillus cereus un valor de $512 \mu \mathrm{g} / \mathrm{ml}$, mientras que frente a Streptococcus agalactiae fue de $128 \mu \mathrm{g} / \mathrm{ml}$, apreciándose que esta última bacteria es más sensible que $B$. cereus al momento de ser evaluada su capacidad para reproducirse, en presencia de componentes antimicrobianos en su medio. 
La fracción clorofórmica generó un efecto bacteriostático sobre la cepa Pseudomonas aeruginosa ATCC 27853 (Figura 2) en cada una de las concentraciones empleadas, se encontró un halo con algunas colonias bacterianas alrededor de cada una uno de los pozos, disminuyendo el crecimiento de esta bacteria.

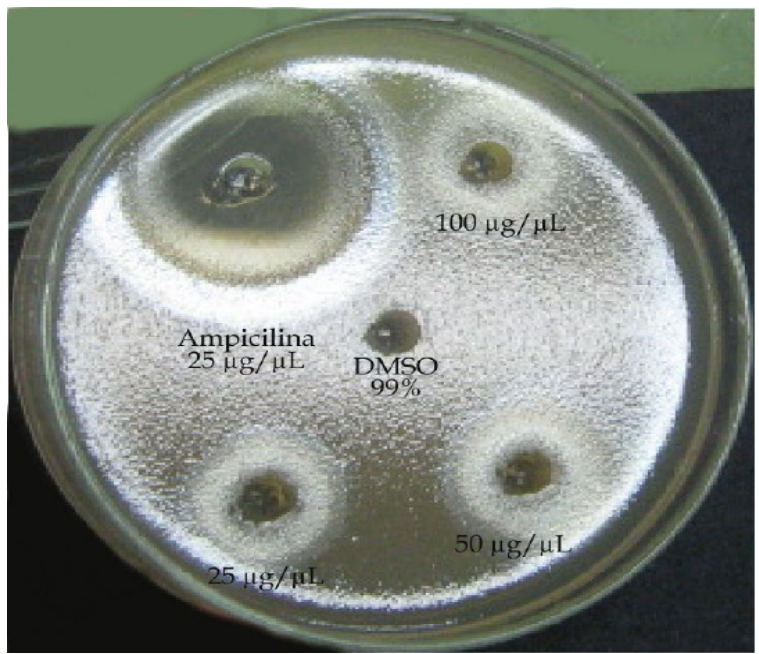

Figura 2. Efecto bacteriostático de la fracción clorofórmica frente a Pseudomonas aeruginosa ATCC 27853

Análisis químico de la fracción clorofórmica. Según el análisis preliminar por cromatografía de capa delgada esta fracción contiene alcaloides. Se evidenció la presencia de teobromina de $R_{f}$ de 0.85 y de teofilina con un $R_{f}$ de 0.36 según los estándares analizados en las mismas condiciones.

Análisis por CLAE de la fracción clorofórmica. Como se aprecia en la figura 3 , en el perfil cromatográfico por CLAE de la fracción clorofórmica, se encontraron teofilina, teobromina y cafeína con base en los tiempos de retención de los estándares y el espectro ultravioleta característico de alcaloides a $270 \mathrm{~nm}$.

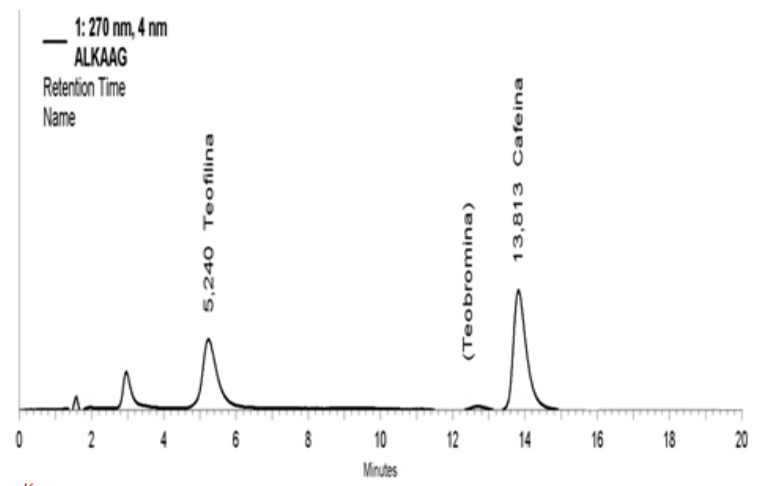

Fígura 3. Perfil cromatográfico por CLAE de la fracción clorofórmica de cáscara de cacao (Theobroma cacao L.)
Los resultados del análisis cuantitativo (Tabla 1 ), indicaron que el compuesto mayoritario en la fracción clorofórmica fue la cafeína. La teobromina se identificó pero no fue posible su cuantificación porque la concentración estuvo por debajo del límite de cuantificación del método.

Tabla 1. Cuantificación de alcaloides por CLAE de la fracción clorofórmica de cáscara de cacao (Theobroma cacao L.). $t_{R}=$ Tiempo de retención. Conc. $=$ Concentración. $\mathrm{NC}=\mathrm{No}$ cuantificada. \%RSD= Desviación estándar relativa.

\begin{tabular}{lccc}
\hline \multicolumn{1}{c}{ Compuesto } & $\mathbf{t}_{\mathbf{R}}(\mathbf{m i n})$ & $\begin{array}{c}\text { Conc. } \\
(\boldsymbol{\mu g} / \mathbf{m L})\end{array}$ & \%RSD \\
\hline Teofilina & $\mathbf{5 . 2 4}$ & $\mathbf{6 . 4 1}$ & $\mathbf{5 . 1 3}$ \\
Teobromina & 12.75 & $\mathrm{NC}$ & 5.29 \\
Cafeína & 13.86 & 10.31 & 5.91 \\
\hline
\end{tabular}

Análisis por CG/EM de la fracción clorofórmica. El análisis se hizo de manera complementaria. En el perfil obtenido (Figura 4 ), se aprecia un pico bien resuelto con un tiempo de retención de 14 minutos que según la comparación con la base de datos Willey 7 versión 2 correspondía a cafeína con un porcentaje de similitud del $96 \%$ y el espectro de masas presentó los fragmentos característicos de la cafeína m/z 194 (pico base), m/z 165, m/z 137, m/z 109, m/z 82, m/z 67 y m/z 55 .

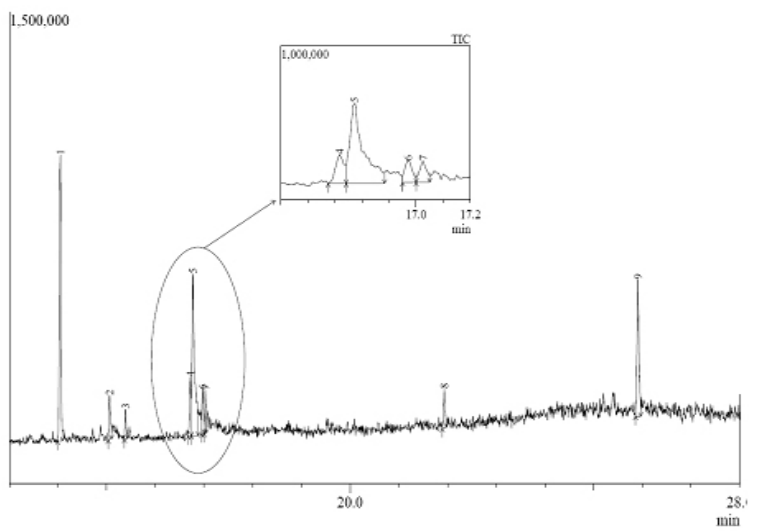

Figura 4. Perfil por CG de la fracción clorofórmica de cáscara de cacao (Theobroma cacao L.)

Análisis químico de las fracciones de acetato de etilo y butanólica. Según el análisis preliminar por cromatografía de capa delgada, se evidenció en ambos casos una mancha de $R_{f} 0.84$ revelada con luz ultravioleta y el ácido ferúlico empleado como referencia reveló con $R_{f} 0.87$, lo que podría indicar la presencia de compuestos de tipo fenólico.

Análisis por CLAE de las fracciones de acetato de etilo y butanólica. Como se aprecia en la figura 5, las dos fracciones 
presentaron perfiles cromatográficos similares. En ambos se encontraron 5 picos comunes, cuatro de ellos con tiempos de retención entre 1.3 a 2.7 minutos que de acuerdo con su espectro ultravioleta (máximos de absorbancia entre 250 y $380 \mathrm{~nm}$ ), pueden corresponder a compuestos de tipo fenólico y un compuesto de tiempo de retención de 5.1 minutos el cual fue identificado según su espectro (máximo de absorbancia a 270 $\mathrm{nm}$ ) como un alcaloide y por comparación con el tiempo de retención del estándar como teofilina.

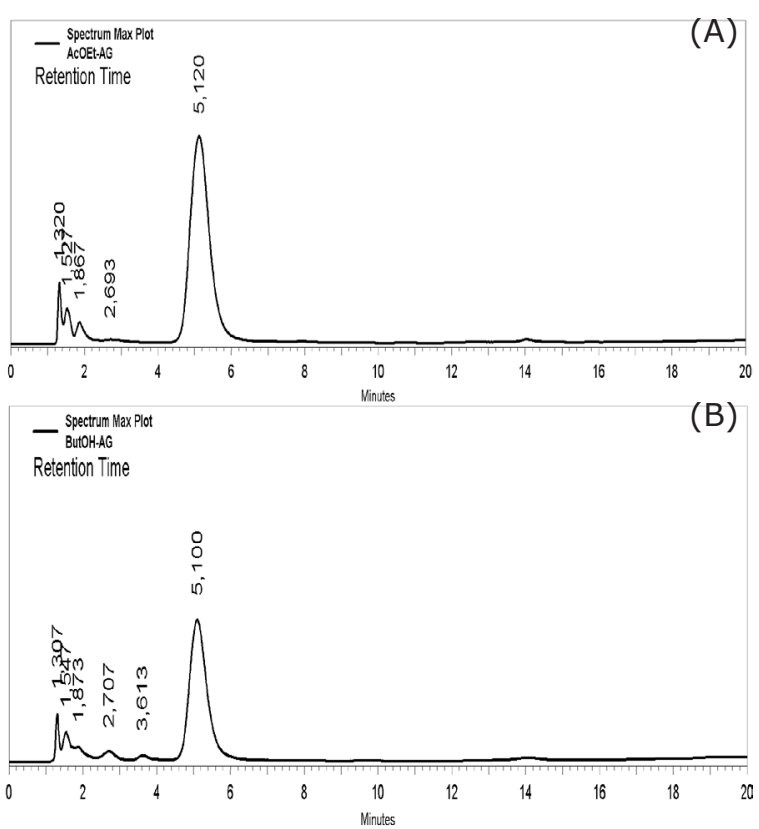

Figura 5. Perfil cromatográfico por CLAE de las fracciones: (A) Acetato de etilo y (B) Butanólica de la cáscara de cacao (Theobroma cacao L.)

Según la cuantificación de estos compuestos (Tabla 2), el mayoritario (5.1* $\mathrm{min}$ ) fue la teofilina y las concentraciones de los compuestos de tipo fenólico se encontraron en un rango de $3.31 \mu \mathrm{g} / \mathrm{ml}$ a $14.32 \mu \mathrm{g} / \mathrm{ml}$.

Tabla 2. Cuantificación de compuestos de tipo fenólico por CLAE de las fracciones de acetato de etilo y butanólica de cáscara de cacao (Theobroma cacao L.). $t_{R}=$ Tiempo de retención. Conc. $A=$ Concentración en la fracción de Acetato de etilo. Conc. $B=$ Concentración en la fracción butanólica.

\begin{tabular}{ccc}
\hline $\begin{array}{c}\mathbf{t R} \\
(\mathbf{m i n})\end{array}$ & $\begin{array}{c}\text { Conc. A } \\
(\boldsymbol{\mu g} / \mathbf{m L})\end{array}$ & Conc. B $(\boldsymbol{\mu g} / \mathbf{m L})$ \\
\hline 1.3 & 10.76 & 8.66 \\
1.5 & 14.32 & 10.85 \\
1.8 & 13.78 & 9.86 \\
2.7 & 3.31 & 5.63 \\
$5.1^{*}$ & 188.64 & 104.32 \\
\hline
\end{tabular}

Actividad antibacteriana de las fracciones de acetato de etilo y butanólica. Estas fracciones no presentaron ningún efecto inhibitorio sobre los microorganismos objeto de estudio.

\section{DISCUSIÓN}

La fracción clorofórmica resultó promisoria ya que presentó actividad antibacteriana frente a los microorganismos Gram positivos estudiados. De acuerdo con los valores de concentración mínima inhibitoria encontrados $(512 \mu \mathrm{g} / \mathrm{ml}$ frente a Bacillus cereus ATCC 11778 y $128 \mu \mathrm{g} /$ $\mathrm{ml}$ frente a Streptococcus agalactiae, según la clasificación de otros autores (20), esta fracción se consideraría como un potente inhibidor. La actividad biológica que exhibió esta fracción puede atribuirse en parte al efecto sinérgico de los alcaloides que la constituyen puesto que existen reportes que evidencian esta característica de este grupo de compuestos $(21,22)$; sin embargo, se requieren otros estudios para profundizar sobre esta actividad.

De otra parte, la fracción clorofórmica presentó efecto bacteriostático frente al microorganismo Gram negativo P. aeruginosa ATCC 27853, observándose en cada pozo un halo circundante de color brillante con presencia de algunas colonias bacterianas observándose que se inhibió el crecimiento de esta bacteria; este resultado concuerda con lo reportado por otros autores (23), que indican, que este microorganismo presenta una alta resistencia a los agentes antimicrobianos; luego sería importante en próximos estudios evaluar concentraciones diferentes de esta fracción a las utilizadas en el presente trabajo que permitan establecer su potencial bactericida.

Los resultados del análisis cuantitativo por CLAE de la fracción clorofórmica de la cáscara de cacao, indicaron que el alcaloide mayoritario fue la cafeína, otros autores han reportado a la teobromina como el alcaloide principal en todo el grano de cacao (24), pero no se encontraron estudios de la distribución de estas metilxantinas en la cáscara; Sin embargo, como indican otros autores (25), la baja solubilidad de la teobromina en solventes polares favoreció el enriquecimiento de cafeína y teofilina en el extracto etanol agua 1:1 obtenido. Además, según estudios muy recientes (26) la cafeína y teofilina forman un complejo con características químicas que podría llegar a correlacionarse en estudios posteriores con la actividad antibacteriana exhibida por esta fracción. 
El análisis por cromatografía de gases acoplado a espectrometría de masas confirmó la presencia de cafeína como el alcaloide mayoritario en la fracción clorofórmica, según sus fragmentos característicos (27).

Las fracciones en acetato de etilo y butanólica no presentaron actividad antibacteriana. Si bien fue posible evidenciar la presencia de compuestos de tipo fenólico con base en su espectro ultravioleta (28), los cuales según reportes de otros autores han exhibido actividad antibacteriana (29); es probable que la concentración de estos compuestos en las fracciones estudiadas $\mathrm{y} / \mathrm{o}$ el hecho de que puedan encontrarse formando glicósidos como lo han indicado estudios previos en el cacao (30), afecte de alguna forma su actividad. Luego sería conveniente realizar nuevos análisis llevando a cabo una hidrólisis de la cáscara de cacao, previa a la extracción para evaluar su actividad.

En conclusión, la fracción clorofórmica resultó promisoria inhibiendo el crecimiento de
Bacillus cereus ATCC 11778 y Streptococcus agalactiae, por tanto, este trabajo es el primer reporte conocido en Colombia sobre actividad antibacteriana in vitro de la fracción clorofórmica de la cáscara de cacao; el cual resulta ser un avance importante para esta agroindustria. Esta investigación abre paso a otros estudios relacionados para establecer el espectro de inhibición frente a otros microorganismos.

\section{Agradecimientos}

Los autores agradecen a Casa Luker por suministrar la cáscara de cacao, a la Vicerrectoría de Investigación y Extensión de la Universidad Tecnológica de Pereira por financiar la investigación, al Laboratorio de Calidad de Productos Naturales de la Universidad Tecnológica de Pereira por los análisis cromatográficos y al Laboratorio ClínicoPatológico López Correa (Pereira, Colombia) por la donación del microorganismo Streptococcus agalactiae.

\section{REFERENCIAS}

1. Singh - Nee Nigam P, Robinson R, Batt C, Patel P. Cocoa and coffee fermentations. In: Encyclop Food Microbiol. London: Academic Press; 2000

2. Quintero ML, Díaz KM. El mercado mundial de cacao. Agroalim 2004; 18:47-59

3. Niemenak N, Rohsius C, Elwers S, Omokolo D, Lieberei R. Comparative study of different cocoa (Theobroma cacao L.) clones in terms of their phenolics and anthocyanins contents. J Food Comp Anal 2006; 19:612-619

4. Edwards H, Villar S, de Oliveira L, Le Hyari M. Analytical Raman spectroscopic study of cacao seeds and their chemical extracts. Anal Chim Acta 2005; 538: 175-180

5. Othman A, Ismail A, Abdul N, Adenan I. Antioxidant capacity and phenolic content of cocoa beans. Food Chem 2007; 100:1523-1530

6. Lipp M, Simoneau C, Ulberth F, Anklam E, Crews $C$, Brereton $P$, et al. Composition of cocoa butter and cocoa butter equivalents. J Food Comp Anal 2001; 14: 399-408
7. Oddoye E, Rhule S, Agyente-Badu K, Anchirinah V, Ansah F. Fresh cocoa pod husk as an ingredient in the diets of growing pigs. Sci Res Essays 2010; 5: 1141-1144

8. Olubamiwa $\mathrm{O}$, Otun A, Longe O, Dietary inclusion rate of cocoa husk for starter cockerels. Int J Poult Sci 2002; 1: 133 - 135

9. Barazarte $H$, Sangronis E, Unai E. La cáscara de cacao (Theobroma cacao L.): una posible fuente comercial de pectinas. Arch Latinoam Nutr 2008; 58: 64-70

10. Padrón G, Arias E, Romero J, Benavides A, Zamora J, García S. Efecto de la cáscara de cacao en la obtención de espumas de poliuretano para uso hortícola. Propiedades físicas y de biodegradabilidad. Rev Soc Quím Méx 2004; 48:156-164

11. Osawa K, Miyazaki K, Shimura S, Okuda J, Matsumoto M, Ooshima T. Identification of cariostatic substances in the cacao bean husk: their anti-glucosyltransferase and antibacterial activities. J Dent Res 2001; 80: 2000-2004 
12. Ito $K$, Nakamura $Y$, Tokunaga $T$, Iijima D, Fukushima K. Anti-cariogenic properties of a water-soluble extract from cacao. Biosci Biotechnol Biochem 2003; 67:2567-2573.

13. Agronet 2010. Análisis - Estadísticas. Área Cosechada, Producción y Rendimiento de Cacao, 2009 - 2010. Ministerio de Agricultura y Desarrollo Rural. Disponible en línea en: http://www.agronet.gov.co/ www/htm3b/ReportesAjax/VerReporte.aspx (Consulta: Enero 31 de 2012)

14. Abarca D, Martínez R, Muñoz J, Torres M, Vargas G. Residuos de café, cacao y cladodio de tuna: Fuentes promisorias de fibra dietaria. Rev Tecnol 2010; 23: 63-69

15. Devendra C, Sevilla C. Availability and use of feed resources in crop-animal systems in Asia. Agr Syst 2002; 71: 59-73

16. Jiménez Díaz S. Efecto de la inclusión de harina de cascarilla de cacao en la elaboración de galletas. [Tesis de Especialización]. Bogotá, Universidad Nacional de Colombia; 2008

17. Pérez Echeverry P. Mucílago pulverizado obtenido a partir de la cáscara de cacao, una alternativa en la clarificación de jugos en la industria panelera. [Tesis de Especialización]. Manizales: Universidad Nacional de Colombia; 2004

18. The National Committee for Clinical Laboratory Standards. Performance standards for antimicrobial disk susceptibility tests. Vol. 23. 8th ed. Wayne: NCCLS; 2003 (NCCLS document M2 - A8)

19. Andrews JM. Determination of minimum inhibitory concentration. J Antimicrob Chemother 2001; 48 (Supl 1):5-16.

20. Aligiannis N, Kalpotzakis E, Mitaku S, Chinou I. Composition and antimicrobial activity of the essential oils of two Origanum species. J Agric Food Chem 2001; 40: 4168 - 4170

21. Al-Janabi A. Potential activity of the purine compounds caffeine and aminophylline on bacteria. J Glob Infect Dis 2011; 3: 133-7
22. Ibrahim SA, Salameh MM, Phetsomphou $\mathrm{S}$, Yang $\mathrm{H}$, Seo CW Application of caffeine, 1,3,7-trimethylxanthine, to control Escherichia coli O157:H7. Food Chem 2006; 99: 645-650

23. Hossein $\mathrm{H}$, Bibi S, Mojgan M. In vitro Evaluation of Methylxanthines and Some Antibiotics: Interaction against Staphylococcus aureus and Pseudomonas aeruginosa. Iran Biomed ] 2006; 10: 163-167

24. Brunetto $M R$, Gutiérrez $L$, Delgado $Y$, Gallignani M, Zambrano A, Gómez A, et al. Determination of theobromine, theophylline and caffeine in cocoa samples by a high performance liquid chromatographic method with on-line sample cleanup in a switchingcolumn system. Food Chem 2007; 100: 459-467

25. Kasabe A, Badhe G. Extraction and estimation of theobromine in marketed tea by HPTLC and uv method. Int J Appl Biol Pharm Tech 2010; 1: $367-373$.

26. Karthika M, Senthilkumar L, Kanakaraju R. Theoretical studies on hydrogen bonding in caffeine-theophylline complexes. Comput Theor Chem 2012; 979: 54-63.

27. Horai $H$, Arita $M$, Kanaya $S$, Nihei $Y$, Ikeda $T$, Suwa $K$, et al. Mass Bank: a public repository for sharing mass spectral data for life sciences. J Mass Spectrom 2010; 45: 703-714.

28. Stalikas C. Extraction, separation, and detection methods for phenolic acids and flavonoids. J Sep Sci 2007; 30: 3268-3295.

29. Bubonja-Sonje M, Giacometti J, Abram $M$. Antioxidant and antilisterial activity of olive oil, cocoa and rosemary polyphenols extract. Food Chem 2011; 127: 1821-1827

30. Sánchez-Rabaneda $F$, Jáurequi $O$, Casals I, Andrés-Lacueva C, IzquierdoPulido M, Lamuela Raventós R. Liquid chromatographic / electrospray ionization tandem mass spectrometric study of the phenolic composition of cocoa (Theobroma cacao). J Mass Spectrom 2003; 38: 35-42 